\title{
PENGARUH WALL BOUNCE INDIVIDU DAN BERPASANGAN TERHADAP KEMAMPUAN DAN SIKAP PASSING BAWAH BOLAVOLI
}

\author{
Sakip ${ }^{1}$, Gempur Santoso ${ }^{2}$, Sumardi ${ }^{3}$ \\ 1,2,3 Program Pascasarjana Universitas PGRI Adi Buana Surabaya \\ Email: sakip@gmail.com¹, gempur_bohar@yahoo.com², Sumardi.ppi@gmail.com³ \\ DOI: https://doi.org/10.36526/kejaora.v5i1.858
}

\begin{abstract}
ABSTRAK
Tujuan penelitian ini untuk mengetahui pembelajaran passing bawah wall bounce individu dan kelompok berpasangan terhadap kemampuan dan sikap passing bawah bolavoli. Jenis penelitian adalah eksperimen, rancangan penelitian pretes post randomized control group desain, populasi dalam penelitian ini adalah siswa SMP Aswaja Legung dan sampel penelitian adalah siswa kelas VIII 40 siswa. Instrumen yang digunakan adalah tes passing bawah selama satu menit. Hasil penelitian menunjukan bahwa uji normalitas data yakni dengan taraf signifikan 0.05 hasil uji lebih besar dari alfa yakni 0,759, 0.988 dan 0.988 berdistribusi normal, uji homogenitas data dengan taraf signifikansi di atas 0.05 hasil uji lebih desar dari alfa, $0.800,0.208,0.232$ sehingga dinyatakan data homogen, yang diteruskan pada hasil analisis multivariate hasil uji manova dengan menggunakan Pillai's, Wilks Lambda, q Hotellingq Tace dan Roy's Largest Rootq didapatkan nilai signifikansi lebih kecil dari $0.05(p<0.05)$ yang artinya terdapat pengaruh yang sangat signifikan. Simpulan dari penelitian bahwa ada pengaruh untuk metode pembelajaran pasing bawah wall bounce individu dan kelompok berpasangan terhadap kemampuan dan sikap pasing bawah bolavoli pada siswa SMP. Kelompok pasing dengan wall bounce memiliki kemampuan pasing lebih baik dan sikap pasing yang lebih baik, dibandingkan kelompok pasing berpasangan.
\end{abstract}

Kata Kunci: Bolavoli, Siswa, Pasing Bawah, Wall Bounce

\section{PENDAHULUAN}

Di kota Sumenep permainan bolavoli menjadi salah satu hiburan masyarakat yang sangat digemari, dan sering diadakan pertandingan bolavoli mulai gala desa, antar kecamatan bahkan open tournament antar klub bolavoli se kabupaten Sumenep. Suasana seperti itu membawa dampak positif untuk anak-anak dan remaja mengenal permainan bolavoli lebih awal yang menginsipirasi mereka bermain dan mengenal lebih jauh permainan tersebut yang pada akhirnya dapat mengembangkan bakat dan minat olahraga khususnya permainan bolavoli yang bisa dapat mengantarkan mereka bisa berprestasi sampai di tingkat nasional, bahkan internasional. Sebagai permainan yang sudah dikenal luas oleh masyarakat tentu banyak anak atau remaja yang sudah terbiasa memainkan bahkan sudah bisa bermain permainan tersebut, selain itu permainan bolavoli sangat mudah dikenal karena keterampilan yang ada dalam permainan tersebut sangat mudah untuk dipraktikkan. Ada keterampilan yang melibatkan kemampuan memukul bola, memantulkan bolavoli, dan keterampilan melompat.

Permainan bolavoli yang sudah dikenal di masyarakat di kabupaten Sumenep, tentu ada dampak pada pengenalan permainan bolavoli sebagai salah satu cabang olahraga permainan yang diajarkan pada mata pelajaran Pendidikan Jasmani Olahraga dan Kesehatan (PJOK). Untuk tingkat Sekolah Menengah Pertama (SMP) permainan bolavoli termuat dalam kurikulum, silabus yang sekaligus menjadi salah satu permainan olahraga bola besar yang sangat disukai dan juga digemari selama oleh siswa khusus di SMP Islam Aswaja Legung Kabupaten Sumenep. Mengapa sangat disukai dan digemari? Karena permainan bolavoli sudah sangat dikenal oleh masyarakat dan juga dikenal oleh anak dan remaja di luar jam pelajaran 
Jurnal Kejaora: Jurnal Kesehatan Jasmani dan Olah Raga

ISSN: 2541-5042 (Online)

ISSN: 2503-2976 (Print)

Volume 5 Nomor 1, Edisi April 2020

sekolah, bermain dan permainan sehari-hari dengan lapangan yang sederhana dapat bermain bolavoli.

Fakta yang ada ditemui nampak berbeda, beberapa siswa yang ada di SMP Islam Aswaja belum menguasai sepenuhnya teknik dasar bolavoli walaupun mereka sudah tahu permainan bolavoli, terutama teknik yang paling mendasar yakni caranya passing. Hal ini disebabkan kurangnnya model pembelajaran yang mengacu langsung pada teknik dasar passing bawah bolavoli. Kunci dasar permainan bolavoli adalah pasing (Mahardika, dkk, 2015). Atas dasar itu maka pembelajaran menjadi suatu alat yang tepat untuk mampu membantu siswa yang ada di SMP Islam Aswaja mampu menguasai teknik dasar permainan bolavoli khususnya pasing. Dengan penguasaaan keterampilan dasar diharapkan anak-anak bisa berpraktik permainan bolavoli baik di sekolah di ekstrakurikuler maupun di luar sekolah, agar bakat minat bisa terasah dan berkembang dengan baik serta bisa berprestasi di kota Sumenep, selain itu untuk membantu Sekolah dan Kabupaten mengikuti berbagai pertandingan yang diadakan oleh daerah maupun provinsi seperti PORSENI, O2SN dan kejuaraan lainnya.

Upaya untuk membantu siswa memiliki kemampuan keterampilan dasar dalam permainan bolavoli adalah bagian dari keharusan untuk mendukung siswa mampu bermain permainan bolavoli awal dengan baik. Dukungan melalui berbagai macam cara untuk memiliki keterampilan dasar dapat dilakukan oleh guru PJOK yang profesional yang didukung oleh sarana prasarana yang memadai dan cukup baik. Namun keterampilan pasing bolavoli masih kurang dari harapan. Hal ini dikarenakan belum mengkolaborasikan sarana dan prasarana agar proses pembelajaran menjadi menarik dan sesuai dengan kebutuhan sesuai dengan perkembangan usia. Menyiapkan keterampilan dasar dalam permainan bolavoli untuk anak Sekolah Menengah Pertama membutuhkan pendekatan yang disesuaikan dengan takaran usia yang masih pemula bahkan perlu ada modifikasi di dalamnya khususnya modifikasi dalam permainan

bolavoli untuk memudah penguasaan teknik dasar (Mutohir, dkk, 2013).

Adapun tujuan penelitian untuk penguasaan keterampilan dasar permainan bolavoli untuk siswa kelas VII di SMP Islam Aswaja Legung Barat Bata-Batang Sumenep adalah (1) untuk mengetahui apakah ada pengaruh pembelajaran pasing bawah wall bounce terhadap sikap dan kemampuan siswa kelas VII Sekolah Menengah Pertama (SMP) VIII SMP Islam Aswaja Legung Barat Batang-Batang Sumenep, (2) Untuk mengetahui apakah ada pengaruh pembelajaran passing bawah secara kelompok berpasangan terhadap sikap dan kemampuan pada saat passing bawah Siswa Kelas VIII SMP Islam Aswaja Legung Barat Batang-Batang Sumenep. (3) Model pembelajaran mana yang lebih baik.

\section{METODE}

Jenis penelitian adalah quasi eksperimen atau setengah eksperimen, yang bertujuan untuk mengetahui pengaruh suatu perlakuan dalam hal ini adalah perlakuan pasing bawah wall bounce. Metode penelitian yang digunakan adalah kuantitatif yakni berdasarkan pengambilan data di lapangan berupa tes pasing bawah, dengan rancangan penelitian menggunakan paradigma ganda yakni melibatkan dua variabel independen dan dua variabel dependen.

Rancangan penelitian yang digunakan dalam penelitian adalah pre test post test control group desain seperti terlihat pada tabel 1. Berdasarkan dari tabel 1 menunjukkan rancangan penelitian kelompok pembelajaran pasing bawah dengan intervensi wallbounce dan praktik pasing bawah.

Populasi dalam penelitian ini adalah siswa kelas VIII SMP Islam Aswaja Legung Barat Batang-Batang, sedangkan teknik pengampulan sampel menggunakan random sampling, dan sampelnya adalah siswa putra kelas VIII yang berjumlah 40 orang siswa. Jumlah sampel yang sudah diperoleh sebanyak 40 siswa putra dibagi menjadi dua kelompok, (1) kelompok pembelajaran passing secara individu, dan (2) kelompok eksperimen yang diberikan pembelajaran wall bounce. 
Untuk pengambilan data, Peneliti menggunakan teknik pengumpulan data secara observasi dengan jenis terus terang, yaitu peneliti dalam melakukan pengumpulan data menyatakan secara terus terang kepada sumber data. Jadi siswa yang diteliti mengetahui sejak awal sampai akhir tentang aktivitas Peneliti (Sugiono, 2015). Berikut ini tahap pengumpulan data tersebut:

1. Menentukan instrumen penilaian untuk tes kemampuan dan sikap dalam melakukan passing bawah bolavoli dengan menggunakan kerangka;

a) Kemampuan passing bawah dihitung dalam satuan menit dengan cara passing bawah secara individu;

b) Tes sikap passing bawah.

2. Melakukan pre test pada sampel yaitu 40 siswa untuk mengetahui masing-masing sikap dan kemampuan mereka sebelum diberikan perlakuan (treatment).

3. Menentukan kelompok kontrol atau pembanding dan kelompok eksperimen.

4. Memberikan pembelajaran passing bawah secara berkelompok dan wall bounce pada kelompok eksperimen.

5. Memberikan pembelajaran passing individu pada kelompok kontrol.

6. Post test dari kedua kelompok untuk melihat kemampuan dan sikap passing bawah bola voli

7. Alat ukur dan tempat berupa stopwach, alat tulis, dan lembar penilaian observasi, sedangkan tempatnya adalah lapangan
SMP VIII SMP Islam Aswaja Legung Barat Batang-Batang Sumenep.

Analisis yang dilakukan dalam kajian ini dimaksudkan untuk menguji hipotesis yang diajukan. Mengacu pada Suharsimi Arikunto (2006), teknik analisis data yang digunakan adalah uji multivariate yang meliputi uji normalitas data, uji homogenitas data, dan diakhiri dengan manova untuk mengetahui efek dari satu perlakuan.

\section{HASIL DAN PEMBAHASAN}

Penelitian dilakukan pada siswa kelas VIII SMP Islam Aswaja Legung untuk kelompok hasil tes wall bounce dengan kemampuan pasing bawah sejumlah 20 Siswa. Ada beberapa tahapan analisis mulai dari persiapan untuk mengolah data awal meliputi rata-rata, kemudian diteruskan dengan melalukan uji normalitas data, uji homogenitas data, setelah dinyatakan normal dan homogen maka dapat diteruskan dengan melakukan uji multivariate yakni manova.

Setelah dilakukan perlakuan selama tiga bulan penuh maka diperoleh gambaran data awal dari perlakukan sebanyak 40 siswa di SMP Islam Aswaja Kelas VIII. Dari data awal tersebut dilanjutkan dengan melakukan tes normalitas data. Adapun data awal dianalisis untuk persiapan seperti terlibat pada tabel hasil uji normalitas data.

Tabel 1. Analisis Awal Pembelajaran Pasing Bawah dan Wall Bounce

\begin{tabular}{lcrrrr}
\hline & N & Minimum & Maximum & Mean & Std. Deviation \\
\hline Pre_test_Eks_WB & 20 & .00 & 1.00 & .8500 & .36635 \\
\hline post_test_KK_WB & 20 & .00 & 1.00 & .2000 & .41039 \\
\hline pre_test_Eks_WB_Pasingbawah & 20 & .00 & 1.00 & .5000 & .51299 \\
\hline post_tes_KK_WB_pasingbawah & 20 & .00 & 1.00 & .1500 & .36635 \\
\hline Pre_test_Eks_KB_PB & 20 & 1.00 & 4.00 & 1.6000 & 1.23117 \\
\hline Post_test_KK_KB_PB & 20 & .00 & 1.00 & .2000 & .41039 \\
\hline Pre_test_Eks_KB_SPB & 20 & .00 & 4.00 & 1.3500 & 1.42441 \\
\hline Post_test_KK_KB_SPB & 20 & .00 & 1.00 & .1500 & .36635 \\
\hline Valid N (listwise) & 20 & & & & \\
\hline
\end{tabular}

Pada tabel 1, menunjukkan dari hasil

eksperimen wall bounce 0.8500 dan post tes data di atas terdapat rata-rata pre tes kelompok kontrol wall bounce 0.2000 , 
Jurnal Kejaora: Jurnal Kesehatan Jasmani dan Olah Raga

ISSN: 2541-5042 (Online)

ISSN: 2503-2976 (Print)

Volume 5 Nomor 1, Edisi April 2020

sedangkan pre tes eksperimen wall bounce pasing bawah 0.5000 dan post tes kelompok kontrol wall bounce pasing bawah 0.1500 , sedangkan pre tes eksperimen kelompok berpasangan pasing bawah 1.6000 dan pos test kelompok kontrol kelompok berpsangan pasing bawah 0.2000 , sedangkan pre tes eksperimen kelompok berpasangan sikap pasing bawah 1.3500 dan pos tes kelompok kontrol kelompok berpasangan sikap pasing bawah 0.1500 .

Setelah dilakukan analisis pada tabel 1 maka dapat dilanjutkan dengan melakukan uji normalitas data, adapun hasil dari analisis uji normalitas data ada pada tabel 2, yang dapat menunjukkan data normal atau tidak.

Tabel 2. Uji Normalitas Data

\begin{tabular}{|c|c|c|c|c|c|c|c|c|c|}
\hline & & س & 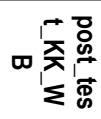 & 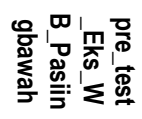 & 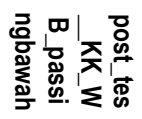 & 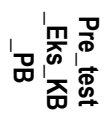 & 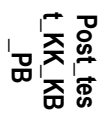 & 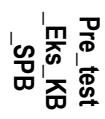 & 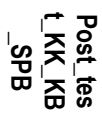 \\
\hline \multirow{3}{*}{ 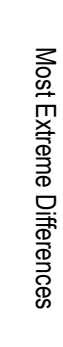 } & 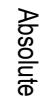 & .300 & .200 & .200 & .100 & .200 & .200 & .500 & 100 \\
\hline & 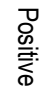 & .300 & .000 & .000 & .000 & .000 & .000 & .000 & .000 \\
\hline & 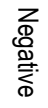 & .000 & -200 & -200 & -100 & -200 & -200 & -.500 & 促. \\
\hline \multicolumn{2}{|c|}{$\begin{array}{l}\text { Kolmogorov- } \\
\text { Smirnov Z }\end{array}$} & .671 & .447 & .447 & .224 & .447 & .447 & 1.118 & .224 \\
\hline \multicolumn{2}{|c|}{$\begin{array}{l}\text { Asymp. Sig. } \\
\text { (2-tailed) }\end{array}$} & .759 & .988 & .988 & 1.000 & .988 & .988 & .164 & 1.000 \\
\hline
\end{tabular}

Berdasarkan data pada tabel 2, maka dapat disimpulkan bahwa hasil uji normalitas pada data penelitian diperoleh nilai signifikan semua lebih besar dari $p$-value 0.05 yang di baca adalah Sig. (2-tailed), maka data berdisitribusi normal pre tes maupun postes.

Tabel 3. Uji Homogenitas Data

\begin{tabular}{ccccc}
\hline & Levene Statistic & df1 & df2 & Sig. \\
\hline Pre_test_Eks_WB & 47.250 & 1 & 18 & .800 \\
\hline post_test_KK_WB & 5.684 & 1 & 18 & .208 \\
\hline pre_test_Eks_WB_Pasiingbawah & .000 & 1 & 18 & 1.000 \\
\hline post_tes_KK_WB_passingbawah & 1.531 & 1 & 18 & .232 \\
\hline Pre_test_Eks_KB_PB & 5.684 & 1 & 18 & .128 \\
\hline Post_test_KK_KB_PB & 5.684 & 1 & 18 & .128 \\
\hline Pre_test_Eks_KB_SPB & 1.863 & 1 & 18 & .189 \\
\hline Post_test_KK_KB_SPB & 1.531 & 1 & 18 & .232 \\
\hline
\end{tabular}

Setelah data dinyatakan normal maka langkah selanjutnya adalah melakukan uji homogenitas data yang menjadi penentu untuk analisis selanjutnya. Berdasarkan data pada tabel di atas, maka dapat disimpulkan bahwa hasil uji homogenitas diperoleh nilai signifikan semua lebih besar dari $p$-value 0.05 , maka data berdisitribusi homogen. Hal ini menunjukan syarat untuk multivariate tes yakni manova, bisa di lanjutkan.

Tabel 4. Hasil Uji Multivariate Tes

\begin{tabular}{clrrrrr}
\hline \multirow{2}{*}{ Intercept } & Effect & Value & F & Hypothesis df & Error df & Sig. \\
\cline { 2 - 7 } & Pillai's Trace & .929 & $28.325^{\mathrm{b}}$ & 6.000 & 13.000 & .000 \\
\cline { 2 - 7 } & Wilks' Lambda & .071 & $28.325^{\mathrm{b}}$ & 6.000 & 13.000 & .000 \\
\hline
\end{tabular}


Jurnal Kejaora: Jurnal Kesehatan Jasmani dan Olah Raga

ISSN: 2541-5042 (Online)

ISSN: 2503-2976 (Print)

Volume 5 Nomor 1, Edisi April 2020

\begin{tabular}{llrrrrr}
\hline & Hotelling's Trace & 13.073 & $28.325^{\mathrm{b}}$ & 6.000 & 13.000 & .000 \\
\cline { 2 - 7 } & Roy's Largest Root & 13.073 & $28.325^{\mathrm{b}}$ & 6.000 & 13.000 & .000 \\
\hline \multirow{3}{*}{ Nilai } & Pillai's Trace & .457 & $1.822^{\mathrm{b}}$ & 6.000 & 13.000 & .172 \\
\cline { 2 - 7 } & Wilks' Lambda & .543 & $1.822^{\mathrm{b}}$ & 6.000 & 13.000 & .172 \\
\cline { 2 - 7 } & Hotelling's Trace & .841 & $1.822^{\mathrm{b}}$ & 6.000 & 13.000 & .172 \\
\cline { 2 - 7 } & Roy's Largest Root & .841 & $1.822^{\mathrm{b}}$ & 6.000 & 13.000 & .172 \\
\hline
\end{tabular}

a. Design: Intercept + Nilai

b. Exact statistic

Berdasarkan tabel 5 yang telah dipaparkan maka berdasarkan hasil uji manova pada kolom di atas dengan menggunakan 4 model statistik meliputi Pillai's, Wilks Lambda, q Hotellingq Tace dan Roy's Largest Rootq didapatkan nilai signifikansi lebih kecil dari $0.05 q \quad(p<0.05)$ yang artinya $\mathrm{HO}$ ditolak atau terdapat pengaruh yang sangat signifikan antara masing-masing variabel.

Berdasarkan penyajian data di atas, maka pembelajaran passing bawah wall bounce berpengaruh terhadap sikap dan kemampuan passing bawah bola voli pada Siswa Kelas VIII SMP Islam Aswaja Legung Barat Batang-Batang Sumenep. Hasil analisis data menunjukkan ada perubahan atau pengaruh yang berarti atau signifikan pada siswa yang mengikuti pembelajaran permainan bolavoli untuk siswa SMP Kelas VIII.

Hasil dari analisis tersebut khususnya pada tabel 5 tentu relevan dengan fenomenafenomena ilmiah yang memadai serta hasil penelitian lain, seperti hasil penelitian Ernailis (2016) menyatakan bahwa keterampilan gerak dasar passing bawah siswa dapat ditingkatkan melalui strategi pembelajaran passing bawah sesama teman. Asri dan Ikhwan Abduh (2016) menyatakan bahwa ada pengaruh yang signifikan tentang penerapan metode langsung terhadap peningkatan hasil belajar passing bawah bola voli pada siswa. Sedangkan Iskandar dan Yulianingsih (2015) menyatakan bahwa metode bermain dalam penguasan pasing sangat mendukung siswa memperoleh peningkatan cara pasing. Pasing memiliki peran penting dalam keterleksanaan permainan bolavoli, setelah servis dilakukan maka pada tahap berikutnya adalah pasing bawah, namun lihat kondisi bola yang datang bisa menggunakan pasing atas, jika penerima servis dengan pasing yang salah maka bisa berdampak pada lawan mendapatkan nilai dalam permainan ini. Permainan bolavoli untuk pasing perlu didukung dengan kemampuan praktik yang cukup banyak, latihan pasing yang berulang-ulang (Muhyi, 2009) agar bisa membantu penguasaan pasing dengan baik

Dengan demikian, bahwa kajian tentang pengaruh metode pembelajaran passing bawah wall bounce individu dan kelompok berpasangan dapat membantu seorang guru PJOK untuk meningkatkan hasil dari kemampuan dan sikap passing bawah bolavoli sehingga siswa yang memiliki kemampuan dan sikap yang kurang dalam pembelajaran passing bawah bola voli dapat terbantu dan sesuai dengan tujuan dari pembelajaran PJOK yang dilakukan di SMP Kelas VIII di SMP Islam Aswaja Legung Barat Batang-Batang Sumenep.

\section{KESIMPULAN}

Dari latar belakang masalah yang telah dikemukakan bahwa kajian ini bertujuan untuk mendapatkan gambaran pengaruh Metode Pembelajaran passing bawah wall bounce individu dan kelompok berpasangan terhadap kemampuan dam sikap passing bawah Bola Voli pada siswa kelas VIII SMP Islam Aswaja Legung Barat Batang Batang Sumenep, maka dapat ditarik kesimpulan bahwa (1) ada pengaruh untuk metode pembelajaran pasing bawah wall bounce individu dan kelompok berpasangan terhadap kemampuan dan sikap pasing bawah bolavoli pada siswa SMP. (2) Kelompok eksperimen yang diberikan perlakuan wall bounce dan kelompok berpasangan lebih baik dibandingkan kelompok kontrol yang hanya diberikan pembelajaran passing bawah terhadap kemampuan pasing dan sikap pasing bawah. (3) Kelompok eksperimen wall bounce berpasangan yang lebih baik daripada wall bounce individu. 
Jurnal Kejaora: Jurnal Kesehatan Jasmani dan Olah Raga

ISSN: 2541-5042 (Online)

ISSN: 2503-2976 (Print)

Volume 5 Nomor 1, Edisi April 2020

\section{SARAN}

Berdasarkan kesimpulan hasil peneitian maka untuk penelitian selanjutnya untuk dapa memodifikasi model pembelajaran dengan memadukan model latihan untuk mendapatkan hasil yang lebih baik.

\section{DAFTAR PUSTAKA}

Abduh, A.I. (2016). Peningkatan Pembelajaran Pasing Bawah Dalam Permainan Bolavoli Melalui Model Pembelajaran Langsung (Direct Instructions) Pada Siswa Kelas V SD No. 1 Pesaku Kecamatan Dolo Barat Kabupaten Sigi, E-Journal Physical Education, Health and Recreation 4 (1) Halaman 1-15.

Ernailis. (2016). "Peningkatan Keterampilan Passing Bawah Bola Voli Melalui Strategi Pembelajaran Sesama Teman Pada Ssiswa Kelas IV SD Negri 001 Empat Balai Kecamatan Kuok Kabupaten Kapar". Jurnal Primary Program Studi Pendidikan Guru Sekolah Dasar Fakultas Keguruan dan IImu Pendidikan Universitas Riau, 05, 60-61.

Mahardika, I.M.G.A, Marhaeni, A.A.I.N, Widiartini, K. (2015). Pengaruh Variasi Pelatihan Passing Terhadap Kemampuan Melakukan Passing Atas Pada Permainan Bolavoli Pada Siswa SMALB SLB B Negeri Sidakarya Tahun Ajaran 2014/2015, e-Jurnal Program Pasca Sarjana Universitas Pendidikan Ganesha, Program Studi Penelitian dan Evaluasi Pendidikan, 5 (1), Halaman 1-8.

Iskandar dan Yulianingsih. (2015). Peningkatan Keterampilan Pasing Atas Dalam Permainan Bolavoli, Melalui Metode Bermain Siswa Kelas VIII SMP Negeri 3 Sungai Ambawang Kabupaten Kubu Raya, Jurnal Pendidikan Olahraga 4 (2) 157-169.

Mutohir, Muhyi, M., dann Djunaidi, S., Lani. (2013). Konsep, Teknik, Metode dan Modifikasi Dalam Permainan BolaVoli, Java Pustaka, Surabaya. 